\title{
Understanding the usage of Mobile Payment Systems- the impact of personality on the continuance usage
}

Conference or Workshop Item

Accepted Version

Almazroa, M. and Gulliver, S. (2018) Understanding the usage of Mobile Payment Systems- the impact of personality on the continuance usage. In: 4th International Conference on Information Management (ICIM), 25-27th May 2018, Oxford University. doi:

https://doi.org/10.1109/INFOMAN.2018.8392833 (2018 4th International Conference on Information Management (ICIM)) Available at http://centaur.reading.ac.uk/78066/

It is advisable to refer to the publisher's version if you intend to cite from the work. See Guidance on citing.

Published version at: https://ieeexplore.ieee.org/document/8392833/

To link to this article DOI: http://dx.doi.org/10.1109/INFOMAN.2018.8392833

All outputs in CentAUR are protected by Intellectual Property Rights law, 
including copyright law. Copyright and IPR is retained by the creators or other copyright holders. Terms and conditions for use of this material are defined in the End User Agreement.

\section{www.reading.ac.uk/centaur}

\section{CentAUR}

Central Archive at the University of Reading

Reading's research outputs online 


\section{Understanding the Usage of Mobile Payment Systems- The Impact of Personality on the Continuance Usage}

\author{
Maram Almazroa \\ Henley Business School \\ University of Reading \\ Reading, UK \\ e-mail: m.n.m.almazroa@pgr.reading.ac.uk
}

\author{
Stephen Gulliver \\ Henley Business School \\ University of Reading \\ Reading, UK \\ e-mail: s.r.gulliver@henley.ac.uk
}

\begin{abstract}
Payment convenience has benefited from the revolution in mobile technologies. M-payment users, however, seem inconsistent in their payment activity, resisting change from traditional payment methods. Ensuring consumer continuance of m-payment technology usage is critical to ensuring the ubiquity of m-payment solutions. Although research has examined the influence of individual difference on the acceptance of m-payment, most studies fail to consider whether ongoing acceptance is maintained by the user, or whether a change in perception occurs as a result of use. Moreover, current studies consider user demographic profiles to segment mobile users, yet this dismisses the impact of individual difference, e.g. personality or cognitive style. This paper proposes a model that can be used to investigate the impact of individual difference on user perception of $\mathbf{m}$ payment systems. The Expectation Confirmation Model (ECM) and Unified Theory of Acceptance and Use of Technology (UTAUT2) model factors (i.e. effort expectancy, performance expectancy, social influence, facilitating condition, habit, hedonic motivation, price value, trust and perceived risk) allow capture of data relating to two use perceptions; pre- and postusage perception. The proposed model allows capture and comparison of pre-usage expectation and post-usage beliefs, allowing consideration of perception variance as a result of technology use. This model will be applied to gain a deeper insight into how to address users' satisfaction, acceptance, and continuance usage of Near Field Communication m-payment technologies.
\end{abstract}

Keywords- continuance adoption, Expectation Confirmation Model (ECM), Near Field Communication m-payment, personality Unified theory of acceptance and use of technology (UTAUT2).

\section{INTRODUCTION}

Mobile technologies are one of the areas that's has seen as the most innovative which has transformed the way consumers interact and rely on their phone for their daily activities [1]. Several mobile technologies and applications have been developed which significantly changed consumer payment behaviour. Near Field Communication (NFC) is a recent technology that enable bi-directional communication where individuals can make a payment by waiving their equipped mobile device with (NFC) chips in front of a NFC equipped payment terminal. This means that mobile device is transform into the medium that actually makes the payments at the payment terminal [2]. NFC has been regarded as the future of m-payment systems and attempted to compete with existing payment methods. The major player of NFC mpayment systems Apple Pay, Android Pay and Samsung Pay are reporting a growth of new users [3]. Due to this growth, it has become very competitive for m-payment service providers to increase their market share and maintain customer satisfaction and retention. Despite the fact that NFC m-payment systems have gained momentum, they have not yet reach the expected potential. For example, according to a recent survey conducted over Apple and Samsung phone users, only $21 \%$ and $14 \%$ respectively with access to NFC m-payment on their smartphone have actually used it and most of them haven't used the service more than once and went back to cards or cash [4]. Previous research have shown that implementing mobile payment is not a simple technical solution, but it is affected by various factors such as social, organizational, individual, behavioural, financial and cultural factors [5]-[7]. Furthermore, it is difficult to identify the psychological and attitudinal process of consumers' payment choice [8]. Therefore, it is crucial to understand psychological process of consumers in order to sustain current customers and satisfy their needs. Although there are several research that examine the adoption at individual level, there are limited research that examines the effect of personality on technology acceptance. The latter is crucial because technology adoption by people is a micro-level matter [9].

Technology acceptance research is one of the most mature research in the discipline of IS. It provides better understanding of different factors that leads to accept or reject a technology. A growing number of empirical studies that considered the behaviour of m-payment user. The majority of the them were focused on initial adoption that empirically validated the well-known adoption and diffusion theories such as TAM, TRA, TPB, DOI and UTAUT using quantitative data [10]-[22]. Chen (2008) expanded the technology acceptance model (TAM) and the Innovation of Diffusion theory (IDT) to examine which factors determined consumer acceptance of m-payment. He found that consumers intention to use m-payment affected by four factors; perceived usefulness, perceived ease of use, perceived risk and compatibility. Compatibility was the strongest determent. It refers to the degree to which m- 
payment fits with user's lifestyle and current needs. Another study by Schierz et al. (2010) who tested TAM with additional construct such as compatibility, perceived security, individual mobility and subjective norm using large scale survey conducted in Germany to determine the key drivers that affect an individual's usage of m-payment. They also found that compatibility had the greatest influence on the intention to use m-payment. Individual mobility and subjective norm also have a significant impact. To date, Schierz et al. (2010) model achieved the highest predictive power in the context of m-payment with $84 \%$ explained variation in the intention to use m-payment. Furthermore, Shin (2010) employed TAM model modified with some constructs form UTAUT. His study propose a conceptual framework of m-payment adoption enablers, drivers and barriers. Many studies included the two determinants of TAM model but with very different findings. Chen \& Chang (2013) revealed in their study that perceived usefulness and social influence had a significant influence on m-payment adoption. This is line with the findings from Teo et al. (2015) where effort expectancy, performance expectancy, facilitating conditions, and trust, are significant determinant to the intention of m-payment adoption. In contrast, a recent study by [16] failed to found any significant influence of perceived ease of use on nonusers' intentions to accept mpayment in the UK. Furthermore, opposite to their assumption [24] didn't find a significant effect of perceived ease of use on perceived usefulness or intentions to adopt.

Three studies used UTAUT model developed by Venkatesh et al. (2003) to examine the adoption of $\mathrm{m}$ payment [26]-[28]. However, none of them studied the effect of the moderating variables as most of the adoption research deploying UTAUT. The only studies founded in the literature conducted by Liébana-cabanillas et al. (2015) and Slade et al. (2014) who have contributed to m-payment adoption research by analysing the impact of user characteristics like age, gender and experience on the use of m-payment in addition to explain the intentions to adopt these payment systems.

According to the critical literature review conducted by Dahlberg et al. (2015) on m-payment research, a list of the adoption factors in the literature is shown in table 1 .

TABLE 1 M-PAYMENT AdOPTION FACTORS AdAPTED From [37]

\begin{tabular}{|l|l|l|l|}
\hline \multicolumn{4}{|l|}{ Constructs } \\
\hline Perceived Ease of Use & Social influence & Trust & $\begin{array}{l}\text { Self- } \\
\text { efficacy }\end{array}$ \\
\hline Perceived Usefulness & Compatibility & Risk & Quality \\
\hline Subjective Norm & Security & Cost & Complexity \\
\hline personal innovativeness & Mobility & Privacy & Knowledge \\
\hline Payment Scenario & Convenience & Experience & Habit \\
\hline
\end{tabular}

Individual differences deemed to be the most significant factors to the success of IS [31]-[33]. Individual differences expected to be related to the usage of $\mathrm{m}$-commerce. Previous research had proposed user-centric model to explore consumers' preferences, motivations and adoption [22], [34]. Demographic aspects are the most common way used to segment users in order to examine their behaviour towards m-commerce usage. Chan \& Chong (2013) found that educational level and age had significant relationships with the use of m-commerce transactions. Faqih \& Jaradat (2015) and Chan \& Chong (2013) failed to find any moderation effect of gender on the adoption process of m-commerce. In the context of m-payments, research mainly considered technology related factor when studying consumer behaviour since m-payment users are users of both payment systems and mobile technologies. Peng et al. (2012) stated that their study is limited to system characteristics and further research including user characteristics is required. Although there are recent research examining the influence of individual differences on the acceptance of m-payment, most of them segment users based on their demographic profiles [15]-[17], [29]. Since NFC m-payment apps are disgned for individual's use, abiquitous and mostly free, factors affect indivual's usage of mobile apps could be different from tradiotional IS adoption factors. Given these findings, further investigation is needed in order to identify whether other consumer segmentation could have an effect on the use of mpayment systems.

Regardless of the huge attention on studying consumer behaviour of mobile services, continuance usage is less studied when compared to the adoption research even though previous studies indicated the importance of understanding the continuance usage [37]. Users of m-commerce could be inconsistent in their actions and not perform the activity again. [35]. Thus, maintaining consumer's continuance usage is critical to m-payment success. Among the few studies of m-payment continuance usage, two leading research were recently conducted in China [38], [39]. China is one of the countries that deployed m-payment earlier and adopted by more users there. Based on IS success model and flow theory, Zhou (2013) found that continuance intention of m-payment is determined by trust, flow and satisfaction while service quality, system quality and information quality indicated as main predecessors affecting trust, satisfaction and flow respectively. The following study revealed that performance expectancy, trust on m-payment systems and flow influence continuance usage.

Through this review of the literature, most of the studies explored the adoption of m-payment in general and not focused on a specific type. However, some m-payment systems are more successful than others, therefore, factors affecting adoption are more likely to be different for different systems of m-payment. This emphasises the importance of differentiating m-payment systems and supporting technologies while exploring consumers' perception towards this new payment method. Continuance behaviour is crucial to the success of m-payment. However, research in this field is less than expected. Furthermore, the majority IS continuance research has ignored consumers' individual differences, However these distinctions are potentially caused user resistance in IS acceptance [40]. To the best of our knowledge, no studies founded that examined the moderating influence of personality traits on the 
continuance adoption of m-payment systems. Thus, this research aims to develop a model that investigate the impact of individuals' personality traits on their perceptions of NFC m-payments and how those thoughts and beliefs have been created through examining users' continuance behaviour to m-payment.

\section{THEORTICAL BACKGROUND}

This section will discuss the theories that help to build this research model. The model is basically based on Information system continuance model by Bhattacherjee (2001), combined with factors from revised theories in current research area. Firstly, this research trends will be discussed. Secondly, relevant theories of personality traits will be examined since this research has a second priority which is examining the possible effect of personality traits on the research model.

\section{A. Expectation Confirmation Model and Related Theories}

Bhattacherjee (2001) proposed his IS continuance model based on the expectation confirmation theory (ECT) developed by Oliver (1980) in marketing research to study the determinants of consumer satisfaction and repurchase behaviour.

Bhattacherjee's expectation confirmation model (ECM) stated that continuance intention is built based on consumer's satisfaction and post usage beliefs, which are both influenced by the confirmation of expectation from consumer's previous use. This model has been used in different IS research [43], [44] and has shown its suitability to study continuance in technology adoption and particularly in mobile commerce context [45], [46]. Furthermore, perceptions regarding needed effort, social influence and usage environment are other potential factors that influence continuance decisions [47]. These factors play a critical role in IS adoption research. However, they are not included in (ECM) for IS continuance.

To study the possible changes in cognitive beliefs and their effects during the stages of usage, Bhattacherjee and Premkumar (2004) developed a two stage model rooted on ECM and place disconfirmation instead of confirmation. Although, perceived usefulness was included as a usage belief, it was the only predictor and other identified factors in IS acceptance models such as TAM and UTAUT were neglected.

Venkatesh et al. (2012) have proposed their new version of UTAUT using a consumer context and adding more determinants. UTAUT2 identifies the endogenous variables behaviour intention and use behaviour studying the extent to which consumers plan and actually use the technology continuously [49]. However, with all these changes, UTAUT models are not developed to explain disconfirmation of user's beliefs or change in satisfaction. Therefore, they are not strong enough to discover continuance decision process [50].

Later, Venkatesh and his colleagues extended the two stage expectation confirmation model developed by [48] by expanding the belief set of the basic ECM to incorporated additional predictors from UTAUT such as effort expectancy, social influence, facilitating conditions and trust beliefs because its relevance to the context of online transaction and sharing sensitive information. This expanded model has provided rich understanding of the continuance decision process by explain a comprehensive elements of beliefs. Furthermore, it stated that changes in the initial perceptions and attitude through disconfirmation and satisfaction constructs are subsequently influence continuance intention [47].

\section{B. Big Five Personality Model}

Personality is defined as a stable set of characteristics that determines people's thought, feelings and behaviours which differentiate each individual from another [51]. The development of an individual's personality is affected by various factors; heredity, social context, geographical and physical condition [52]. It is argued that people have different perceptions and responses to similar actions based on their personality traits. This indicates that personal characteristics affect individual's adoption of new technologies. However, $\mathrm{Xu}$ et al. (2015) revealed that only few research had investigate the influence of personality traits on people's intentions and behaviour towards innovation acceptance and usage.

Several models and dimensions has been developed to measure personality traits. Raymond Cattell's proposed a two-tiered structure for personality involved sixteen primary factors and five secondary factors. In contrast, Hans Eysenck believed that only three traits; extraversion, neuroticism and psychoticism were sufficient to explain people's personality. Digman (1990) developed five factor models of personality which incorporate all findings in personality psychology's research which in turn provided a rich conceptual framework. These models considered as a broader taxonomy for all issues related to personality. The Big Five model is the most widely used model that demonstrated to have a strong explaining variance in behaviour decision [53]. This model can claim to be comprehensiveness due to the many empirical studies including Big Five model compared to other personality models [55]. There are more than 3000 studies including Big Five model that showed the powerful predictive validity [56]. Therefore, Big Five model is suitable to study the effect of personality on behaviour. The model consists of five dimensions; extraversion, neuroticism, agreeableness, conscientiousness, and openness to experience [57]. A definition of each traits is represented in table 2 .

TABLE II. BIG FIVE TRAITS DEFINITION ADAPTED From [33]

\begin{tabular}{|l|l|}
\hline \multicolumn{1}{|c|}{ Big Five Trait } & \multicolumn{1}{|c|}{ Trait Description } \\
\hline $\begin{array}{l}\text { Openness to } \\
\text { experience }\end{array}$ & $\begin{array}{l}\text { People scoring high on the openness scale are } \\
\text { characterized by such attributes as open-mindedness, } \\
\text { active imagination, preference for variety, and } \\
\text { independence of judgment." }\end{array}$ \\
\hline Conscientiousness & $\begin{array}{l}\text { People scoring high on the conscientiousness scale } \\
\text { tend to distinguish themselves for their } \\
\text { trustworthiness and their sense of purposefulness and } \\
\text { of responsibility. They tend to be strong-willed, task- } \\
\text { focused, and achievement-oriented. }\end{array}$ \\
\hline$\underline{E}$ Extraversion & $\begin{array}{l}\text { People scoring high on the extraversion scale tend to } \\
\text { be sociable and assertive, and they prefer to work } \\
\text { with other people. }\end{array}$ \\
\hline
\end{tabular}




\begin{tabular}{|l|l|}
\hline Agreeableness & $\begin{array}{l}\text { People scoring high on the agreeableness scale tend } \\
\text { to be tolerant, trusting, accepting, and they value and } \\
\text { respect other people's beliefs and conventions. }\end{array}$ \\
\hline$\underline{\text { Neuroticism }}$ & $\begin{array}{l}\text { People scoring high on the neuroticism scale tend to } \\
\text { experience such negative feelings as emotional } \\
\text { instability, embarrassment, guilt, pessimism, and low } \\
\text { self-esteem }\end{array}$ \\
\hline
\end{tabular}

\section{RESEARCH MODEL AND HYPOTHESES}

In order to achieve the research objectives, two models; ECM and UTAUT2 were integrated with personality values. The proposed model keeps the basic structure of ECM and involved predictors from UTAUT2 (see figure 1). This study argues that individual's continuance intention towards NFC m-payments is influenced by consumer satisfaction, effort expectancy, performance expectancy, social influence, facilitating condition, habit, hedonic motivation, price value, trust and perceived risk. The effect of those constructs work directly or indirectly on continuance intention under the impact of individual's personality traits as specified by Big Five model [56]. This section will explain the factors of the proposed model and the relationships between them, then the possible influence from individual personality traits.

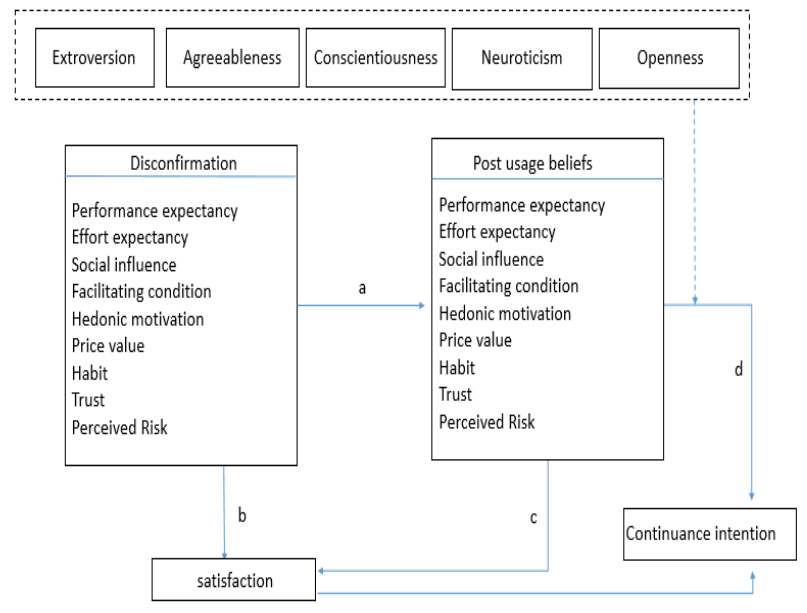

Figure 1 Research Model

From an ECM viewpoint, individual's continuance intention is affected by user satisfaction and post usage beliefs, while satisfaction is determined by confirmation of expectation from initial use. These backbone constructs have been empirically studied and confirmed in several consumer behaviour research. Recently, the relevant relationships have been confirmed to be significant in the context of mcommerce [38], [39], [44], [45]. To accomplish with the literature, this study keeps those variables and relationships in the research model.

Hypothesis 1. Individual's level of satisfaction with NFC m-payments has a positive impact on their continuance intention.

Venkatesh et al (2003) proposed a detail oriented model by combining eight models for technology adoption. This model is built on the four core constructs; performance expectancy, effort expectancy, social influence and facilitating condition. Later, Venkatesh et al. (2012) extended their model with three further constructs; hedonic motivation, price value and habit. UTAUT2 has been validated by several studies at multiple time for different technologies in various context. In term of correlation among the determinants of UTAUT2, there is proof of change in measurements over time for performance expectancy, effort expectancy, social influence and facilitating condition [47]. This indicates that pre usage beliefs could be disconfirmed and such disconfirmation will influence future behaviour. However, not all predictors in UTAUT2 have been examined from the perspective of ECM. Although, previous research in technology acceptance has studied these factors at different point in time, only limited research considered disconfirmation and its consequences. Therefore, this research will examine disconfirmation incorporating UTAUT2 beliefs.

Figure 1 represents the proposed model. Each factor from the nine belief factors included in both post usage and disconfirmation will have four hypotheses (a, b, c, d). The hypotheses for the first factor is represented below and the rest eight factors will follow the same relationships except negative relationships for perceived risk and its associated constructs.

Hypothesis 2a. Disconfirmation of performance expectancy expectation has an impact on post usage performance expectancy perception regarding $\mathrm{NFC} \mathrm{m-}$ payment systems.

Hypothesis 2b. Disconfirmation of performance expectancy expectation has an impact on user satisfaction with NFC m-payment systems.

Hypothesis 2c. Post usage performance expectancy perception has an impact on user satisfaction with NFC mpayment systems.

Hypothesis 2d. Post usage performance expectancy perception has an impact on continuance intention towards NFC m-payment systems.

From personality viewpoint, several studies believed that five personality traits could be a strong determinant and moderator of mobile users' perceptions and the entire network of their behaviour decisions. Hypothesis regarding the impact of personality traits are grouped by factors of Big five model. The moderating effects of each traits on the relationships between post usage beliefs and continuance intention are still under progression. The work that has been done so far is one relationships for the moderating effect of the extraversion personality traits as shown below.

Individuals with conscientious traits are self-disciplined. This implies that they will be more careful when decide to use a technology. They will assess the opportunity of further achievement and productivity by using this technology and then act based on that. Therefore, highly conscientious people will magnify their post usage believes and boost their continuance behavior intention.

Hypothesis 10. The relationships between post usage believes and continuance intention towards NFC mpayments is moderated by the conscientious traits such that 
the relationship is stronger for individuals who get a high score in terms of the conscientious scale.

Individuals scoring high on openness factor are likely to think of creative way on performing tasks. In the context of technology acceptance, openness people are curious to try new technology. Because of their creative aspect, they are likely to continue try new payment method.

Hypothesis 11. The relationships between post usage believes and continuance intention towards NFC mpayments is moderated by the openness to experience traits such that the relationship is stronger for individuals who get a high score in terms of the conscientious scale.

Highly agreeableness individuals are generally like to cooperate with others and have a strong need for social harmony. They show high level of trust towards organisation and authority. Therefore, they would believe that the use of m-payment would be easy and help would be available from technical structure when needed. Furthermore, Mcelory(2007) stated that highly agreeable people would keep trying using ICT even though with frustrating use due to their forgiving nature.

Hypothesis 12. The relationships between post usage believes and continuance intention towards NFC mpayments is moderated by the agreeableness traits such that the relationship is stronger for individuals who get a high score in terms of the conscientious scale.

Extraversion traits implies energetic approach towards how individual interact with others. People with extraversion traits are characterized to be sociable, assertive, talkative and friendly. They are easier to build relationships and used technology to communicate and build new relationships with other [56]. Zmud (1979) stated that extraverts had more positive attitude towards technology than others. The finding from the literature regarding this factor is mixed. Svendsen et al. (2013)and Devaraj et al. (2008)found that extraversion impacted behaviour intention through subjective norm, perceived usefulness and ease of use in TAM model. In contrast, Mcelroy et al. (2007) found no significant impact for extraversion in an integrated TAM and UTAUT model. Currently, mobile social media is widely used and people are connected more frequently. Therefore, mobile users exposed to the social influence on the move and at any time. This leads to the following hypothesis.

Hypothesis 13. The relationship between post usage social influence and continuance intention towards NFC mpayments is moderated by the extraversion traits such that the relationship is stronger for individuals who get a high score in terms of the extroversion scale.

Neuroticism individuals are generally having negative nature and characterised by different activities such as anxiety, depression, stress and nervousness. They have negative feelings towards new things. In terms of adopting technology, Venkatesh and his colleagues reported that neurotic individuals strongly resist change and have negative feeling towards ICT that they have not experience before [60]. Such people could find advances in technology as stressful and threatening in their payment experience and would not be helpful in their financial performance.
Therefore, this trait could have a strong impact on the preusage stage rather than the continuance usage of m-payment which is the context of this study. Thus, this paper will not hypothesize this traits with the post usage beliefs and continuance intention. However, it is included in the research model for the sake of completeness of Big Five Model.

\section{CONCLUSION, CONTRIBUTION AND FUTURE WORK}

In this paper, factors that influence continuance usage of NFC m-payments are identified; such as effort expectancy, performance expectancy, social influence, facilitating condition, habit, hedonic motivation, price value, trust and perceived risk will be explored from two different views; as a post usage perceptions and as confirmation of expectations prior use. The main contribution of this research is the development of m-payment continuance model with the study and analysis of Big Five personality traits and their impact on the continuance usage of NFC m-payment systems. From the practical viewpoint, this model will provide strategic recommendation for service providers with deeper insights into how to address users' satisfaction and continued usage. Future research is needed in order to empirically validate the proposed conceptual model. Although large number of factors have been found to influence the adoption of m-payment, this study is only limited to UTAUT2 factors with trust and perceived risk. Furthermore, this study is also limited to the influence of personality traits as an individual difference and ignore any other differences such as gender, educational level and individual culture.

\section{REFERENCES}

[1] A. Smith, A. L. Project, and J. Q. Anderson, "The future of money: Smartphone swiping in the mobile age," Pew Res. Center's Internet Am. Life Proj., 2012.

[2] M. Pellegrino and L. Zompetti, "Mobile proximity payment 5 things retailers should know," 2016.

[3] S. Blum, "5 mobile-payment trends to watch in 2017," mobilepaymentstoday, 2016. [Online]. Available: https://www.mobilepaymentstoday.com/articles/5-mobile-paymenttrends-to-watch-in-2017/. [Accessed: 04-Feb-2018].

[4] C. Martin, "Tried Mobile Payments: Apple Pay 21\%, Samsung Pay 14\%," MediaPost, 2015.

[5] D. L. Amoroso and R. Magnier-Watanabe, "Building a Research Model for Mobile Wallet Consumer Adoption: The Case of Mobile Suica in Japan," J. Theor. Appl. Electron. Commer. Res., vol. 7, no. 1, pp. 13-14, 2012.

[6] M. Silic, A. Back, and C. Ruf, "Mobile contactless payments adoption challenge in the complex network actor ecosystem 1 Introduction," 27th BLED (Bled Electron. Commer. Conf., pp. 306$317,2014$.

[7] A.-C. Teo, G. W.-H. Tan, K.-B. Ooi, and B. Lin, "Why consumers adopt mobile payment? A partial least squares structural equation modelling (PLS-SEM) approach," Int. J. Mob. Commun., vol. 13, no. 5, pp. 478-497, 2015.

[8] H. Bhatti, A. Abareshi, and S. Pittayachawan, "An Evaluation of Customer Repurchase Behaviour in Mobile Telecommunication Services in Australia," in IEEE IEEM, 2016, pp. 602-606.

[9] M. Srite and E. Karahanna, "The role of espoused national cultural values in technology acceptance," Mis Q., vol. 30, no. 3, pp. 679-704, 2006. 
[10] S. G. Dewan and L. Chen, "Mobile Payment Adoption in the Us : a Cross-Industry Cross-Platform Solution," J. Inf. Priv. Secur., vol. 1, no. October, pp. 4-28, 2005.

[11] L. Chen, "A model of consumer acceptance of mobile payment," Int. J. Mob. Commun., vol. 6, no. 1, pp. 32-52, 2008.

[12] P. G. Schierz, O. Schilke, and B. W. Wirtz, "Understanding consumer acceptance of mobile payment services: An empirical analysis," Electron. Commer. Res. Appl., vol. 9, no. 3, pp. 209-216, 2010.

[13] D.-H. Shin, "Modeling the Interaction of Users and Mobile Payment System: Conceptual Framework," Int. J. Human-Computer Interact. Sungkyunkwan Univ. Seoul, Korea, vol. 26, no. 10, pp. 917-940, 2010.

[14] L. Goeke and K. Pousttchi, "A scenario-based analysis of mobile payment acceptance," Ninth Int. Conf. Mob. Bus. / Ninth Glob. Mobil. Roundtable, pp. 371-378, 2010.

[15] R. Peng, L. Xiong, and Z. Yang, "Exploring tourist adoption of tourism mobile payment: An empirical analysis," J. Theor. Appl. Electron. Commer. Res., vol. 7, no. 1, pp. 21-33, 2012.

[16] E. Slade, M. Williams, Y. Dwivedi, and N. Piercy, "Exploring consumer adoption of proximity mobile payments," J. Strateg. Mark., vol. 4488, no. May, pp. 1-15, 2014.

[17] C. Kim, M. Mirusmonov, and I. Lee, "An empirical examination of factors influencing the intention to use mobile payment," Comput. Human Behav., vol. 26, no. 3, pp. 310-322, 2010.

[18] E. Teo, B. Fraunholz, and C. Unnithan, "Inhibitors and facilitators for mobile payment adoption in Australia: A preliminary study," in Proceedings of the International Conference on Mobile Business, ICMB, 2005, pp. 663-666.

[19] K. Pousttchi, "Conditions for acceptance and usage of mobile payment procedures," in Proceedings of the Second International Conference on Mobile Business, 2003, pp. 201-210.

[20] J. Ondrus, K. Lyytinen, and Y. Pigneur, "Why mobile payments fail? Towards a dynamic and multi-perspective explanation," Proc. 42nd Annu. Hawaii Int. Conf. Syst. Sci. HICSS, pp. 1-10, 2009.

[21] G. De Kerviler, N. T. M. Demoulin, and P. Zidda, "Adoption of instore mobile payment: Are perceived risk and convenience the only drivers?," J. Retail. Consum. Serv., vol. 31, pp. 334-344, 2016.

[22] T. T. Wei, G. Marthandan, A. Y.-L. Chong, K.-B. Ooi, and S. Arumugam, "What drives Malaysian m-commerce adoption? An empirical analysis," Ind. Manag. Data Syst., vol. 109, no. 3, pp. 370388, 2009.

[23] K. Chen and M. Chang, "User acceptance of " near field communication' mobile phone service : an investigation based on the ' unified theory of acceptance and use of technology ' model," Serv. Ind., vol. 33, no. 6, pp. 609-623, 2013.

[24] N. Koenig-lewis, M. Marquet, A. Palmer, and A. Lifen, "Enjoyment and social in fl uence: predicting mobile payment adoption," Serv. Ind., vol. 35, no. 10, pp. 537-554, 2015.

[25] V. Venkatesh, M. G. Morris, G. B. Davis, and F. D. Davis, "User acceptance of information technology: Toward a unified view.," MIS $Q$., vol. 27, no. 3, pp. 425-478, 2003.

[26] P. Hongxia, X. Xianhao, and L. Weidan, "Drivers and barriers in the acceptance of mobile payment in China," in E-Business and EGovernment (ICEE), International Conference on. IEEE, 2011, pp. $1-4$.

[27] L. Wang and Y. Yi, "The Impact of Use Context on Mobile Payment Acceptance: An Empirical Study in China," in In Advances in computer science and education, Springer Berlin Heidelberg, 2012, pp. 293-299.

[28] R. Thakur, "Customer adoption of mobile payment services by professionals across two cities in India: An empirical study using modified technology acceptance model.," Bus. Perspect. Res., vol. 1, no. 2, pp. 17-30, 2013.

[29] F. Liébana-cabanillas, I. R. De Luna, F. J. Montoro-, F. Liébanacabanillas, I. R. De Luna, and F. J. Montoro-ríos, "User behaviour in QR mobile payment system: the QR Payment Acceptance Model
User behaviour in QR mobile payment system : the QR Payment Acceptance Model," Technol. Anal. Strateg. Manag., vol. 27, no. 9, pp. 1031-1049, 2015.

[30] T. Dahlberg, J. Guo, and J. Ondrus, "A critical review of mobile payment research," Electron. Commer. Res. Appl., vol. 14, no. 5, pp. 265-284, 2015.

[31] R. Zmud, "Individual differences and MIS success: a review of the empirical literature," Manage. Sci., vol. 25, no. 10, pp. 966-979, 1979.

[32] R. Agarwal and J. Prasad, "Are individual differences Germane to the acceptance of new information technologies?," Decis. Sci., vol. 30, no. 2, pp. 361-391, 1999.

[33] H. Sun and P. Zhang, "The role of moderating factors in user technology acceptance," Int. J. Human-Computer Stud., vol. 64, no. 4, pp. 53-78, 2006.

[34] A. Zmijewska, E. Lawrence, and R. Steele, "Classifying m-payments - a user-centric model," in The Third International Conference on Mobile Business, 2004.

[35] F. T. S. Chan and A. Y.-L. Chong, "Analysis of the determinants of consumers' m-commerce usage activities," Online Inf. Rev., vol. 37, no. 3, pp. 443-461, 2013.

[36] K. Faqih and M.-I. Jaradat, "Assessing the moderating effect of gender differences and individualism-collectivism at individual-level on the adoption of mobile commerce technology: TAM3 perspective," J. Retail. Consum. Serv., vol. 22, pp. 37-52, 2015.

[37] K. Varnali and A. Toker, "Mobile Marketing Research: The-State-ofthe-Art," Int. J. Inf. Manage., vol. 30, no. 2, pp. 144-151, 2010.

[38] T. Zhou, "Understanding the determinants of mobile payment continuance usage," Ind. Manag. Data Syst., vol. 114, no. 6, pp. 936048, 2014.

[39] T. Zhou, "An empirical examination of continuance intention of mobile payment services," Decis. Support Syst., vol. 54, no. 2, pp. 1085-1091, 2013.

[40] S. Wang, "Impact of IT on Organizations," Hum. Syst. Manag., vol. 16, no. 2, pp. 83-90, 1997.

[41] A. Bhattacherjee, "Understanding Information Systems Continuance: An Expectation-Confirmation Model," MIS Q., vol. 25, no. 3, pp. 351-370, 2001.

[42] R. L. Oliver, "A congitive model of the antecedents and consequences of satisfaction decisions," J. Mark. Res., pp. 460-469, 1980.

[43] M.-C. Lee, "Explaining and predicting users' continuance intention toward e-learning: An extension of the expectation-confirmation model," Comput. Educ., vol. 54, no. 2, pp. 506-516, 2010.

[44] H. Tsai, T. Jui-lin, and M. Chien, "The influences of system usability and user satisfaction on continued Internet banking services usage intention : empirical evidence from Taiwan," Electron Commer Res, vol. 14, pp. 137-169, 2014.

[45] C. Hsiao, J. Chang, and K. Tang, "Exploring the influential factors in continuance usage of mobile social Apps: Satisfaction, habit, and customer value perspectives," Telemat. Informatics, vol. 33, no. 2, pp. 342-355, 2016.

[46] A. P. Oghuma, C. F. Libaque-Saenz, and Y. Chang, "An expectationconfirmation model of continuance intention to use mobile instant messaging," Telemat. INFORMATICS, vol. 33, no. 1, pp. 34-47, 2016.

[47] V. Venkatesh, J. Y. L. Thong, F. K. Y. Chan, P. J. Hu, and S. A. Brown, "Extending the two-stage information systems continuance model: incorporationg UTAUT predictors and the role of context," Inf. Syst. J., vol. 21, pp. 527-555, 2011.

[48] A. Bhattacherjee and G. Premkumar, "Understanding Changes in Belief and Attitude Toward Information Technology Usage: A Theoretical Model and Longitudinal Test," MIS Q., vol. 28, no. 2, pp. 229-254, 2004.

[49] V. Venkatesh, J. Thong, and X. Xu, "consumer acceptance and use of information technology: extending the unified theory of acceptance and use of technology," mis q., vol. 36, no. 1, pp. 157-178, 2012. 
[50] J. Lu, J. Wei, C. Yu, and C. Liu, "How do post-usage factors and espoused cultural values impact mobile payment continuation?," Behav. Inf. Technol., pp. 1-25, 2016.

[51] E. J. Phares and W. F. Chaplin, Introduction to personality, Fourth. New York: Longman, 1997.

[52] V. Özbek, Ü. Aln, F. Koc, M. E. Akk, and E. Ka, "The Impact of Personality on Technology Acceptance: A Study on Smart Phone Users," Soc. Behav. Sci., vol. 150, pp. 541-551, 2014.

[53] R. Xu, R. Manuel, E. Fleisch, and A. Ilic, "Understanding the Impact of Personality Traits on Mobile App Adoption - Insights from a Large-Scale Field Study," in Twenty-Third European Conference on Information Systems (ECIS), 2015.

[54] J. Digman, "Personality structure: emergence of the five-factor model," Annu. Rev. Psychol., vol. 41, no. 1, pp. 417-440, 1990.

[55] G. B. Svendsen, J. K. Johnsen, and L. Alma, "Personality and technology acceptance: the influence of personality factors on the core constructs of the Technology Acceptance Model," Behav. Inf. Technol., vol. 32, no. 4, pp. 323-334, 2013.
[56] O. P. Jhon, L. P. Nauman, and C. J. Soto, "Paradigm Shift to the Integrative Big Five Trait Taxonomy: history, measurement and conceptual issues," in Handbook of Personality: Theory and Research, New York: Guilford Press, 2008.

[57] O. P. John and S. Srivastava, "The Big Five Trait Taxonomy: History, Measurement, and Theoretical Perspectives," Handb. Personal. Theory Res., vol. 2, no. 1, pp. 102-138, 1999.

[58] S. Devaraj, R. Easley, and J. Crant, "How does personality matter? Relating the five-factor model to technology acceptance and use," Inf. Syst. Res., vol. 19, no. 1, pp. 93-105, 2008.

[59] J. C. Mcelroy, A. R. Hendrickson, A. M. Townsend, and S. M. Demarie, "Dispositional factors in internet use: personality versus cognitive style," MIS Q., vol. 31, no. 4, pp. 809-820, 2007.

[60] V. Venkatesh, T. A. Sykes, and S. Venkatraman, "Understanding eGovernment portal use in rural India: role of demographic and personality characteristics," Inf. Syst. J., vol. 24, no. 3, pp. 249-269, 2012 . 